\title{
Ignition of Kerosene Vapor in Supersonic Flow around a Cylinder with an End Windward Wall
}

\author{
Yu.V. Tunik, G.Ya. Gerasimov \\ Institute of Mechanics, M.V. Lomonosov Moscow State University, \\ Moscow, 119192, Russia \\ tunik@imec.msu.ru,gerasimov@imec.msu.ru
}

\begin{abstract}
The detonation capacity of kerosene vapor is numerically studied in supersonic flow around a circular cylinder with an end windward wall. The model of kerosene combustion in the air takes into account 68 reactions for 44 components. Its testing is made by the way of comparison with the available calculated and experimental data on the ignition delay time under adiabatic conditions at a constant density. The mathematical model flow past cylinder is based on twodimensional non-stationary Euler equations for a multi-component reacting gas. The enthalpy and entropy of the initial mixture and combustion products are determined by polynomials from the NASA base. Calculations are performed on the basis of the Godunov finite-difference scheme and its modification of increased accuracy. The results allow justifying the parameters of the nozzle with a central body for a supersonic direct-flow chamber with detonative combustion of kerosene.
\end{abstract}

Keywords: kerosene, detailed kinetics, supersonic flow, ignition, initiation of detonation, detonation combustion, numerical simulation

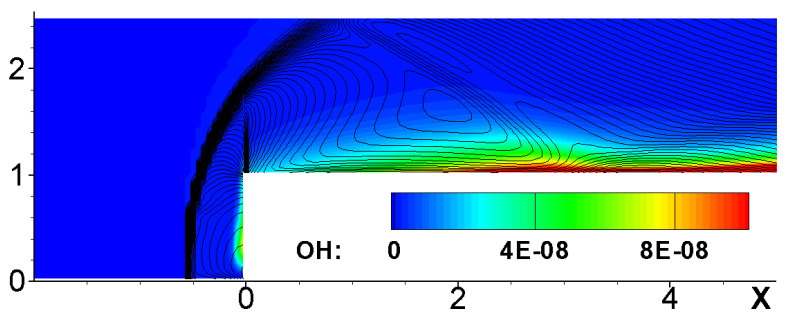

$a$

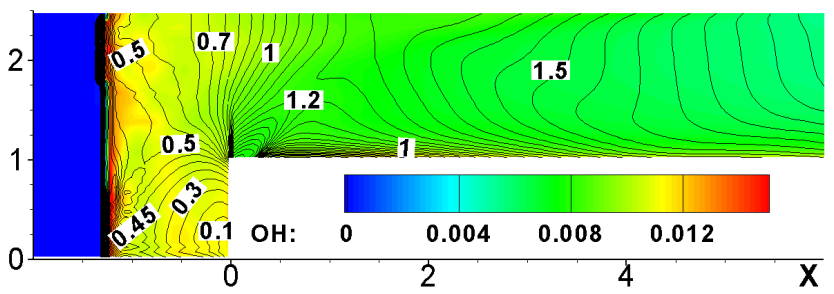

$c$

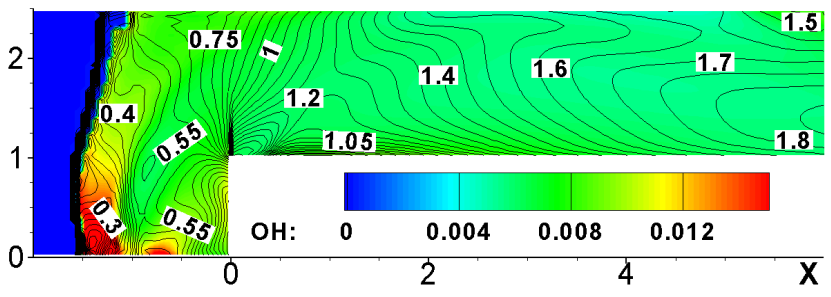

$b$

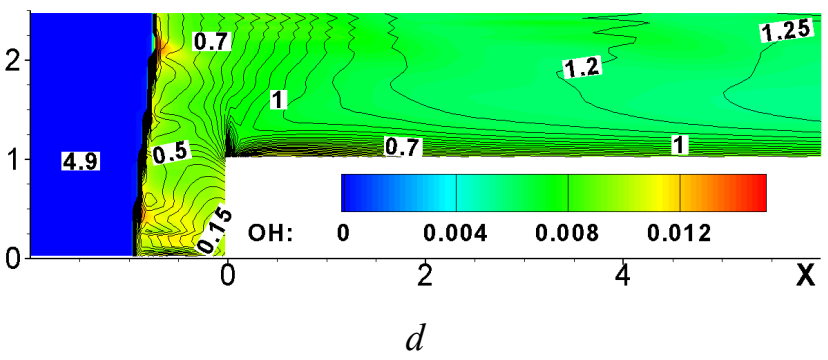

Lines of constant Mach number on the background of $\mathrm{OH}$ mass fraction in the case if the cylinder radius $r_{0}$ is equal to $2 \mathrm{~cm}$ and the Mach number of incident flow of kerosene-air mixture $\mathrm{M}_{0}$ is equal to $3.5(a)$, $4(b), 5(c), 6(d)$ 
УДК 533.6.01+519.6

\title{
Воспламенение паров керосина при сверхзвуковом обтекании цилиндра с торцевой наветренной стенкой
}

\author{
Ю.В. Туник, Г.Я. Герасимов \\ НИИ механики, Московский Государственный Университет им. М.В. Ломоносова, \\ Россия, Москва, 119192, Мичуринский проспект д.1 \\ tunik@imec.msu.ru,gerasimov@imec.msu.ru
}

\begin{abstract}
Аннотация
В работе численно исследуется детонационная способность паров керосина при сверхзвуковом обтекании кругового цилиндра с торцевой наветренной стенкой. Модель горения керосина в воздухе учитывает 68 реакций для 44 компонент. Ее тестирование проводится путем сравнения с имеющимися расчетными и экспериментальными данными по времени задержки воспламенения в адиабатических условиях при постоянной плотности. В основе математической модели обтекания - двумерные нестационарные уравнения Эйлера для многокомпонентного реагирующего газа. Энтальпия и энтропия исходной смеси и продуктов горения задаются многочленами из базы NASA. Расчеты выполняются на основе конечно-разностной схемы С.К. Годунова и ее модификации повышенной точности. Результаты позволяют обосновать параметры сопла с центральным телом для прямоточной камеры детонационного горения керосина.
\end{abstract}

Ключевые слова: керосин, детальная кинетика, сверхзвуковое обтекание, воспламенение, инициирование детонации, детонационное горение, численное моделирование

\section{1. Введение}

Разработка гиперзвуковых летательных аппаратов инициирует исследования детонационного горения, которое по некоторым оценкам, может быть более эффективным, чем медленное или турбулентное (см., например, [1-2]). В [3-8] показана возможность использования детонационного горения водородовоздушных смесей в сверхзвуковой прямоточной камере горения. Однако в авиации в качестве основного топлива традиционно используется керосин, который характеризуется низкой детонационной способностью. В [9-12] детонационная способность керосина или насыщенных углеводородов экспериментально исследуется на базе пульсирующих детонационных двигателей, где инициирование детонации представляет собой самостоятельную задачу.

В сверхзвуковой прямоточной камере сгорания набегающий поток обладает высокой кинетической энергией, которую можно использовать для инициирования детонационного горения керосина. Как правило, керосин впрыскивается в камеру сгорания в дисперсном виде. Однако в случае мелкодисперсной смеси, дробление и испарение капель может происходить быстрее, чем процесс воспламенения паров керосина, скорость которого в первую очередь определяется скоростью разложения тяжелых газообразных углеводородов. Численные исследования по горению паров и тем более капель керосина в сверхзвуковых потоках, как правило, выполняются на базе глобальных кинетических моделей (см., например, [13-15]). Примером использования детальных моделей таких, как [16-18], могут служить расчеты [19]. 
В данной работе численно исследуется детонационная способность паров керосина при обтекании кругового цилиндра с торцевой наветренной стенкой сверхзвуковым коаксиальным потоком, как в открытом пространстве, так и в канале постоянного сечения. Используется детальная кинетическая модель горения керосина. Интерес представляют поперечные размеры канала и скорость потока, обеспечивающие детонационное сжигание поступающей смеси.

\section{2. Кинетическая модель горения паров керосина в воздухе}

\section{1. Компонентный состав и термодинамика смеси}

Компонентный состав керосина зависит от исходного состава перерабатываемой нефти, а также от нефтехимических процессов, применяемых при ее переработке. Керосин состоит в основном из алифатических предельных углеводородов (парафинов), алициклических углеводородов (нафтенов) и ароматических углеводородов (аренов). В керосине присутствуют также различные примеси в виде соединений кислорода, азота и серы, содержание которых в керосине невелико, но в ряде случаев они могут отрицательно сказываться на эксплуатационных свойствах топлива. Групповой и элементный состав отечественных марок керосина приведен в таблице 1, где представлены также данные по низшей теплоте сгорания керосина $[20]$.

Таблицуа 1

Физико-химические характеристики керосина

\begin{tabular}{|c|c|c|c|c|c|c|}
\hline \multirow{2}{*}{ Керосин } & \multicolumn{3}{|c|}{ Групповой состав, мас.\% } & \multicolumn{2}{|c|}{ Элементный состав } & \multirow{2}{*}{$\underset{\text { кДж/кг }}{Q,}$} \\
\hline & парафины & нафтены & Арены & $\mathrm{C}$, мас. $\%$ & $\mathrm{H}$, мac. $\%$ & \\
\hline $\mathrm{T}-1$ & $24 \div 42$ & $42 \div 69$ & $14 \div 20$ & $86.2 \div 86.5$ & $13.5 \div 13.7$ & 43000 \\
\hline TC-1 & $42 \div 52$ & $30 \div 49$ & $11 \div 21$ & $85.7 \div 85.8$ & $14.0 \div 14.1$ & 43290 \\
\hline PT & $53 \div 58$ & $25 \div 30$ & $12 \div 22$ & $85.8 \div 86.1$ & $13.9 \div 14.2$ & 43370 \\
\hline $\mathrm{T}-8$ & $21 \div 50$ & $26 \div 5$ & $14 \div 18$ & $85.8 \div 86.0$ & $13.9 \div 14.1$ & 43290 \\
\hline $\mathrm{T}-6$ & $12 \div 20$ & $75 \div 80$ & $3 \div 6$ & $85.4 \div 86.0$ & $13.4 \div 13.6$ & 43160 \\
\hline $\mathrm{T}-2$ & $40 \div 43$ & $42 \div 50$ & $14 \div 16$ & $85.5 \div 85.7$ & $14.3 \div 14.5$ & 43230 \\
\hline
\end{tabular}

Типичными представителями линейных предельных углеводородов в компонентном

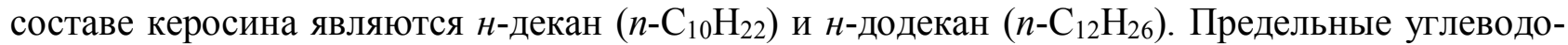
роды с разветвленной цепью представлены в основном изо-октаном $\left(i-\mathrm{C}_{8} \mathrm{H}_{18}\right)$. Алициклические углеводороды присутствуют в основном в виде моноциклических соединений таких, как циклогексан $\left(c y-\mathrm{C}_{6} \mathrm{H}_{12}\right)$ и метилциклогексан $\left(\mathrm{CH}_{3} c y-\mathrm{C}_{6} \mathrm{H}_{11}\right)$. Содержание ароматических углеводородов в керосине ограничивается в связи с их повышенной склонностью к образованию нагара. Наибольшую концентрацию из них имеют толуол $\left(\mathrm{CH}_{3}-\mathrm{C}_{6} \mathrm{H}_{5}\right)$ и этилбензол $\left(\mathrm{C}_{2} \mathrm{H}_{5}-\mathrm{C}_{6} \mathrm{H}_{5}\right)[21]$.

В последние годы предпринимаются многочисленные попытки по разработке однокомпонентных и многокомпонентных суррогатных топлив с соответствующими детальными кинетическими механизмами, моделирующими горение авиационного керосина (см., например, [22-24]). В частности, предложенная в работе [24] суррогатная смесь, используемая для расчета воспламенения синтетического керосина, состоит из 17\% 2,7-диметилоктана, 32\% 2метилдекана, $15 \%$ н-пропилциклогексана и $36 \%$ н-декана.

В [25] проанализированы литературные данные по моделированию горения авиационного керосина различными суррогатными смесями в различных условиях проведения про- 
цесса. Результаты сравнительного анализа показали, что в качестве однокомпонентного суррогатного топлива, достаточно хорошо описывающего воспламенение авиационного керосина, можно использовать $\boldsymbol{\mu}$-декан. В настоящей работе используется упрощенный механизм

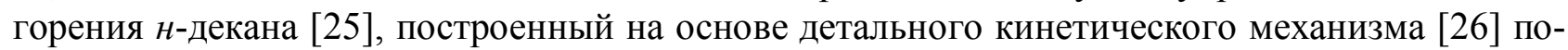
сле исключения из него низкотемпературных химических реакций окисления алифатических углеводородов и реакций окисления бензола.

Для расчета тепловых эффектов в камере сгорания, а также для вычисления констант скоростей обратных химических реакция требуется информация по термодинамическим свойствам индивидуальных химических компонентов реагирующей смеси. В настоящей работе используются хорошо себя зарекомендовавшие при расчете различных высокотемпературных процессов термодинамические данные NASA [27], в которых термодинамические функции индивидуальных компонентов представляются в виде семичленных полиномов от температуры, дающих хорошую аппроксимацию в интервале температур от 150 до $3000 \mathrm{~K}$.

Семичленные полиномы NASA [27] используются для вычисления теплоемкостей $C_{p}^{0}$, энтальпий $H_{T}^{0}$ и энтропий $S_{T}^{0}$ индивидуальных компонентов химически реагирующей системы, а также констант равновесия $K_{c}$ химических реакций как функций температуры. Соответствующие формулы имеют вид

$$
\begin{aligned}
& C_{p}^{\circ} / R=a_{1}+a_{2} T+a_{3} T^{2}+a_{4} T^{3}+a_{5} T^{4}, \\
& H_{T}^{\circ} / R T=a_{1}+a_{2} T / 2+a_{3} T^{2} / 3+a_{4} T^{3} / 4+a_{5} T^{4} / 5+a_{6} / T, \\
& S_{T}^{\circ} / R=a_{1} \ln T+a_{2} T+a_{3} T^{2} / 2+a_{4} T^{3} / 3+a_{5} T^{4} / 4+a_{7}, \\
& G_{T}^{\circ} / R T=H_{T}^{\circ} / R T-S_{T}^{\circ} / R=a_{1}(1-\ln T)-a_{2} T / 2-a_{3} T^{2} / 6- \\
& \quad-a_{4} T^{3} / 12+a_{5} T^{4} / 20+a_{6} / T-a_{7} .
\end{aligned}
$$

Следует отметить, что энтальпия $H_{T}^{\circ}$ связана с энтальпией образования $\Delta_{f} H_{298}^{\circ}$ соотношением

$$
H_{T}^{\circ}=\Delta_{f} H_{298}^{\circ}+\int_{298}^{T} C_{p}^{\circ} \mathrm{d} T
$$

Термодинамический потенциал Гиббса $G_{T}^{\circ}$ можно использовать для вычисления константы равновесия химической реакции в терминах концентраций участвующих в ней компонентов с помощью выражения

$$
\begin{gathered}
K_{c}=(R T)^{-\Delta v} \exp (\Delta W), \\
\Delta W=\Delta a_{1}(\ln T-1)+\frac{\Delta a_{2} T}{2}+\frac{\Delta a_{3} T^{2}}{6}+\frac{\Delta a_{4} T^{3}}{12}+\frac{\Delta a_{5} T^{4}}{20}-\frac{\Delta a_{6}}{T}+\Delta a_{7}
\end{gathered}
$$

Здесь $\Delta v$ - изменение числа молей в химической реакции, а $\Delta a_{i}=\sum v_{j} a_{i j}-$ изменение коэффициентов $a_{i}$. Суммирование проводится по всем реагентам и продуктам реакции со стехиометрическими коэффициентами $v_{j}$, которые являются положительными для продуктов реакции и отрицательными для реагентов. 


\section{2. Инициирующие реакции}

В соответствии с имеющимися кинетическими схемами высокотемпературного разложения $\boldsymbol{\mu}$-декана, высокотемпературное окисление молекулы $\boldsymbol{H}$-декана инициируется реакцией ее взаимодействия с молекулой $\mathrm{O}_{2}$ с образованием соответствующего децилового радикала и радикала $\mathrm{HO}_{2}$ [26]. Вследствие симметричности молекулы $\boldsymbol{\mu - д е к а н а ~ м о г у т ~ о б р а з о в ы в а т ь с я ~}$ пять различных дециловых радикалов, из которых наиболее устойчивым является втордециловый радикал $s-\mathrm{C}_{10} \mathrm{H}_{21}$. Большая степень устойчивости втор-децилового радикала обусловлена единственным каналом $\beta$-распада этого радикала [28]. Следует также отметить, что при температурах выше $1200 \mathrm{~K}$ время жизни алкильных радикалов уменьшается до $10^{-8} \mathrm{c}$. Поэтому при высоких температурах внутреннее распределение образующихся дециловых радикалов становится не важным. В настоящей работе на основании данных $[18,25,26]$ рассматриваются только два дециловых радикала, образующиеся в реакции взаимодействия $\boldsymbol{H}$ декана с молекулой кислорода

$$
\begin{gathered}
n-\mathrm{C}_{10} \mathrm{H}_{22}+\mathrm{O}_{2} \rightarrow s-\mathrm{C}_{10} \mathrm{H}_{21}+\mathrm{HO}_{2}, \\
n-\mathrm{C}_{10} \mathrm{H}_{22}+\mathrm{O}_{2} \rightarrow t-\mathrm{C}_{10} \mathrm{H}_{21}+\mathrm{HO}_{2}
\end{gathered}
$$

с константой скорости $k_{\mathrm{O}_{2}}=1.0 \times 10^{14} \exp (-24000 / T) \mathrm{cm}^{3} /($ моль $)$ ) [18, 26].

В молекуле $н$-декана имеется пять различных С-С связей, разрыв которых при высоких температурах инициирует образование различных углеводородных радикалов с меньшей длиной цепи. В соответствии с принятой в настоящей работе кинетической схемой горения керосина [25], в число инициирующих реакций включены реакции высокотемпературного разложения $\mu$-декана с образованием радикалов $n-\mathrm{C}_{3} \mathrm{H}_{7}, p-\mathrm{C}_{4} \mathrm{H}_{9}, p-\mathrm{C}_{6} \mathrm{H}_{13}$ и $p-\mathrm{C}_{7} \mathrm{H}_{15}$

$$
\begin{aligned}
n-\mathrm{C}_{10} \mathrm{H}_{22} & \rightarrow p-\mathrm{C}_{4} \mathrm{H}_{9}+p-\mathrm{C}_{6} \mathrm{H}_{13}, \\
n-\mathrm{C}_{10} \mathrm{H}_{22} & \rightarrow n-\mathrm{C}_{3} \mathrm{H}_{7}+p-\mathrm{C}_{7} \mathrm{H}_{15}
\end{aligned}
$$

с константой скорости $k=3.16 \times 10^{16} \exp (-40765 / T) \mathrm{c}^{-1}[18,26]$. В число реакций инициирования включены также реакции образования дециловых радикалов при высокотемпературном распаде молекулы $\mu$-декана

$$
\begin{aligned}
n-\mathrm{C}_{10} \mathrm{H}_{22} & \rightarrow s-\mathrm{C}_{10} \mathrm{H}_{21}+\mathrm{H}, \\
n-\mathrm{C}_{10} \mathrm{H}_{22} & \rightarrow t-\mathrm{C}_{10} \mathrm{H}_{21}+\mathrm{H}
\end{aligned}
$$

с константой скорости $k=8.0 \times 10^{17} \exp (-50800 / T) \mathrm{c}^{-1}[18,29]$.

\section{3. Полная схема химической кинетики}

Реакции инициирования (1-4), рассмотренные в предыдущем разделе, ведут к образованию алкильных радикалов, которые в дальнейшем претерпевают разложение на более мелкие радикалы и, в конечном счете, к наработке активных гидроксильных радикалов ОН. Гидроксильные радикалы и атомы Н, образующиеся в реакциях (5-6), взаимодействуют с молекулами $н$-декана, моделирующего керосин, приводя к отщеплению атомов Н от исходной молекулы с образованием втор- и трет-дециловых радикалов $s-\mathrm{C}_{10} \mathrm{H}_{21}$ и $t$ - $\mathrm{C}_{10} \mathrm{H}_{21}$, которые выбраны в принятой кинетической модели в качестве основных.

Представленная схема разложения молекул $н$-декана справедлива для высокотемпературного окисления исходного топлива. Можно выделить основные классы реакций в высокотемпературном механизме: (a) - мономолекулярный распад молекулы исходного топлива с образованием двух алкильных радикалов или децилового радикала и атома $\mathrm{H}$; (б) - отщепление атома Н от молекулы исходного топлива при ее взаимодействии с радикалами ОН и атомами Н с образованием децилового радикала, которое играет важную роль, как при высоких, так и в низких температурах; (в) - $\beta$-распад алкильного радикала с образованием молекулы 
олефина и более мелкого алкильного радикала; (г) - взаимодействие алкильного радикала с молекулой кислорода с образованием олефина и радикала $\mathrm{HO}_{2}$ [21]. Разветвление цепи при высокотемпературном окислении $н$-декана происходит в реакции: $\mathrm{H}+\mathrm{O}_{2} \rightarrow \mathrm{OH}+\mathrm{O}$.

В низкотемпературной области $(T \leq 850 \mathrm{~K})$ высокие энергии активации, связанные с $\beta$ распадом алкильных радикалов, делают высокотемпературную часть механизма окисления $H$-декана более медленной. В этих условиях наиболее важной реакцией является присоединение к алкильному радикалу молекулы $\mathrm{O}_{2}$ с последующим внутренним отщеплением атома $\mathrm{H}$ (Н-сдвиг), вторичным присоединением молекулы $\mathrm{O}_{2}$ и распадом образовавшегося аддукта. В конечном счете проблема окисления алифатических углеводородов и, в том числе, $\mu$-декана сводится к окислению низших алкильных радикалов (метила и этила) в подсистемах $\mathrm{H}_{2} / \mathrm{O}_{2} / \mathrm{CO}$ и $\mathrm{C}_{1} / \mathrm{C}_{2}$. Эта часть кинетического механизма является лимитирующей и ответственна за подобие пламен всех алифатических углеводородов. Полная схема химических реакций, описывающая окисление н-декана [30], приведена на рис. 1.

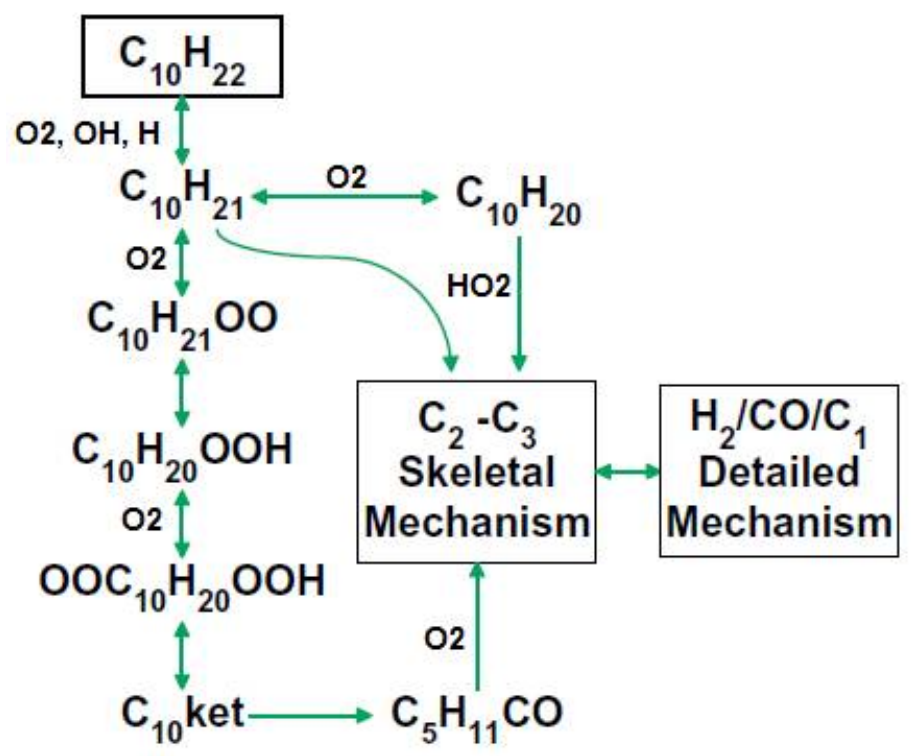

Рис. 1. Схема окисления н-декана в высокотемпературной и низкотемпературной области [30]

Кинетическая модель процесса, являющаяся частью более общей газодинамической модели, должна быть, с одной стороны, предельно упрощена, а с другой, достаточно точно моделировать поведение химически реагирующей системы. В ряде случаев идеальным является сведение кинетического механизма к одной или нескольким брутто-стадиям, даже если такая аппроксимация действует в очень узком диапазоне изменения параметров процесса. Принятая в настоящей работе кинетическая модель горения керосина в воздухе учитывает 68 химических реакций для 44 компонент. Полный список химических реакций с соответствующими кинетическими параметрами приведен в Приложении 1.

\section{4. Время задержки воспламенения в адиабатических условиях}

Методика численного интегрирования двумерных нестационарных течений с неравновесными химическими реакциями предполагает, что на шаге по времени изменение состава смеси происходит в адиабатических условиях при постоянной плотности и внутренней энергии газа в расчетной ячейке [31]. В этих условиях воспламенение паров керосина в воздухе происходит в два этапа. На первом этапе, который соответствует времени задержки воспламенения, температура смеси практически не меняется (рис. 2). При высокой начальной температуре можно заметить и временное снижение температуры, обусловленное разложением тяжелых фракций керосина (рис. $3, a$ ). На втором этапе воспламенение переходит в горение с 
наработкой продуктов горения (рис. 3, б). Переход происходит за короткое время по сравнению со временем задержки воспламенения. Длительность задержки воспламенения определяется положением максимального градиента кривых изменения температуры. Расчетные кривые (рис.4) согласуются с данными экспериментов [30] при температуре выше $1100 \mathrm{~K}$, что соответствует условиям за сильными ударными волнами.

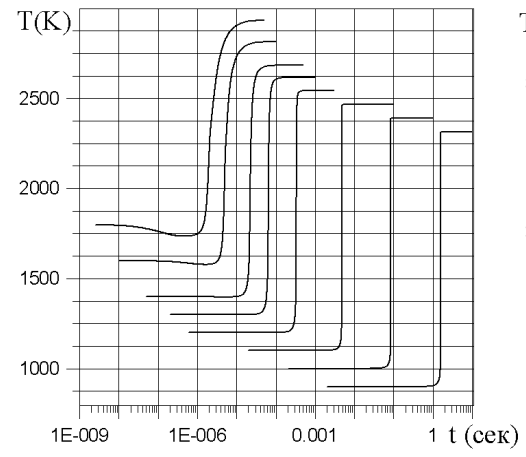

$a$

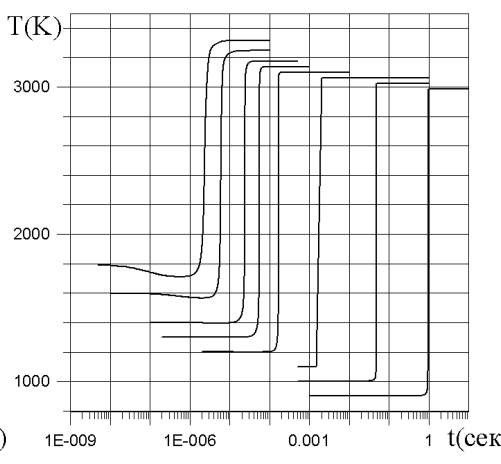

$\sigma$

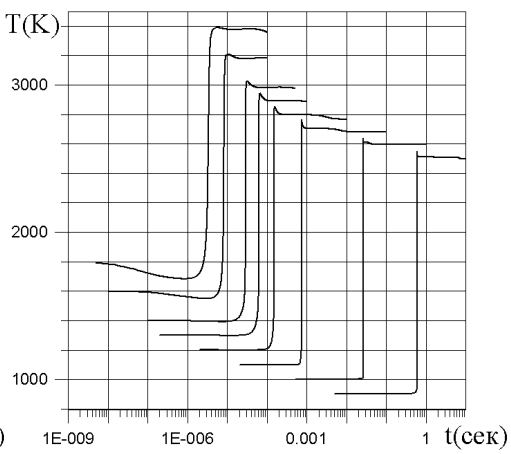

Рис. 2. Изменение температуры при адиабатическом воспламенении смесей с различным значением коэффициента избытка топлива в условиях постоянной плотности и начальном давлении $p_{0}=13$ атм: $a-\varphi=13 ; \sigma-\varphi=1 ; в-\varphi=2$

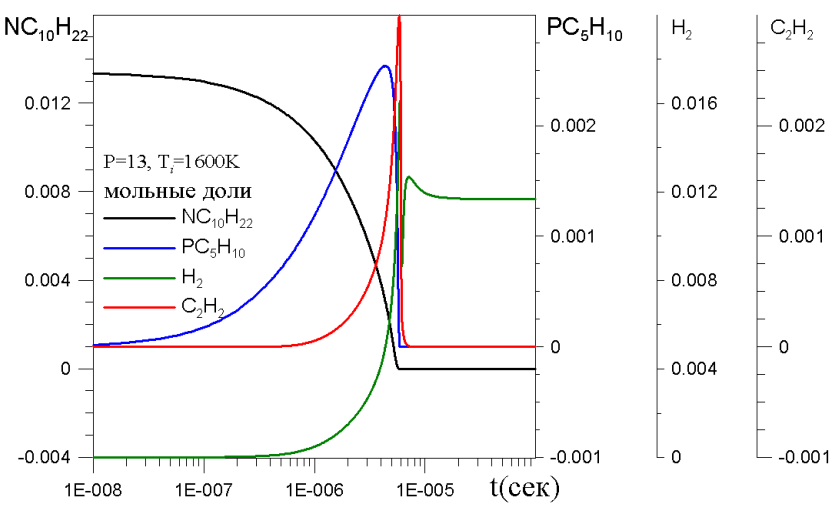

$a$

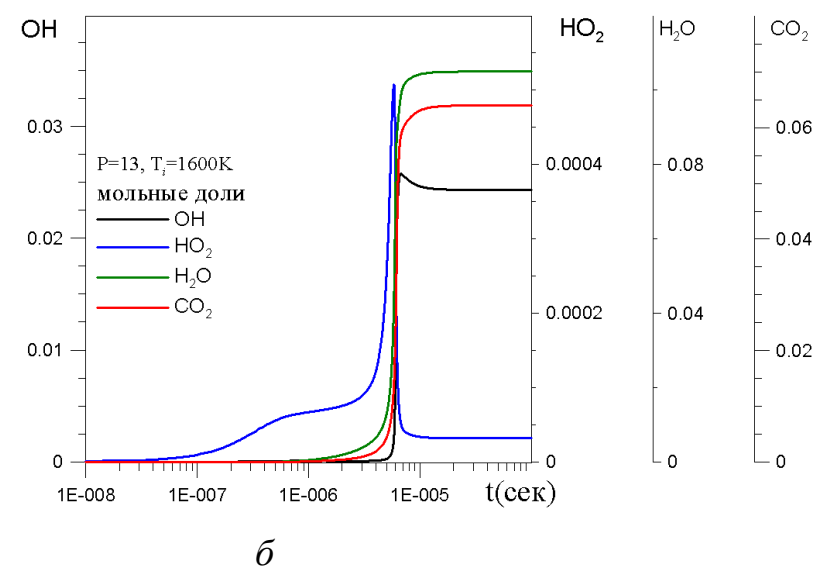

$\sigma$

Рис. 3. Изменение массовой доли компонент смеси при $p_{0}=13$ атм и $T=1600 \mathrm{~K}: a$ - горючие компоненты; $\sigma$ - продукты горения

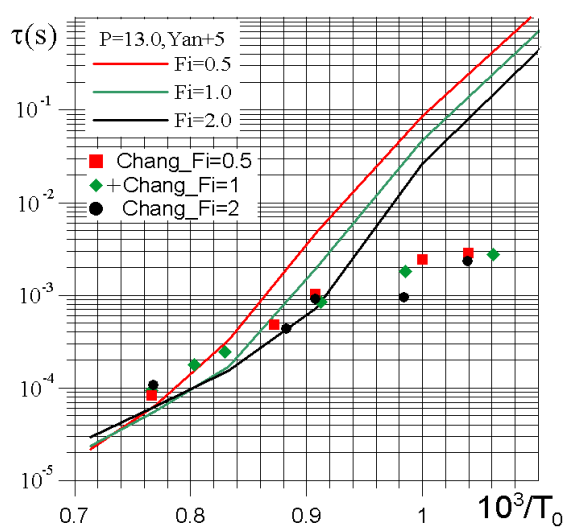

Рис. 4. Зависимость времени задержки воспламенения от температуры инициирования при $p_{0}=13$ атм и различных значениях коэффициента избытка топлива $\varphi$ : точки - эксперимент; линии - расчет по принятой кинетической модели 


\section{3. Постановка задачи обтекания кругового цилиндра сверхзвуковым потоком и метод решения}

В данной работе представленная кинетическая модель используется в задаче обтекания кругового цилиндра с торцевой стенкой сверхзвуковым потоком стехиометрической смеси паров керосина с воздухом. Движение газа описывается двумерными нестационарными уравнениями Эйлера для осесимметричных течений многокомпонентной смеси с химическим реакциями. Расчеты проводятся по программе, разработанной на основе конечноразностной схемы Годунова первого порядка точности [32]. В некоторых случаях для сравнения используется схема Колгана второго порядка аппроксимации по пространственным координатам на гладких решениях [33], а также модификация схемы Годунова-Колгана с промежуточной точкой [34-35] для задания газодинамических параметров в задаче распада произвольного разрыва. Положение этой промежуточной точки задается параметром $\beta$. Ниже в расчетах $\beta=2$. В [35] подробно обсуждается эффективность $\beta$-модификации на примере обтекания кругового цилиндра с торцевой стенкой коаксиальным сверхзвуковым потоком однокомпонентного газа, проводится ее сравнение со схемами Годунова и Колгана по локальной точности расчетов.

Расчетная область в плоскости $(X, Y)$ ограничена осью симметрии, контуром цилиндра, прямыми линиями $X_{1}=-2, X_{2}=4$, а также горизонтальной прямой $Y=5$ или $Y=R$ в случае, когда цилиндр находится в коаксиальной трубе радиуса $R$ (рис. 5). Здесь и ниже длины и расстояния отнесены к радиусу цилиндра $r_{0}=L_{0}$. Расчеты выполняются на прямоугольной равномерной сетке с заданным числом $N_{y}$ ячеек вдоль торцевой стенки.

Граничные условия на входе в расчетную область, то есть при $X=X_{1}$, не меняются во времени. Задана скорость $u_{0}$ набегающего потока, давление $p_{0}=1$ атм и температура $T_{0}=300 \mathrm{~K}$. Скорость $u_{0}$ определяется скоростью звука в смеси и числом Маха $\mathrm{M}_{0}$ воздушного потока при тех же значениях давления и температуры. На оси симметрии, поверхности цилиндра и трубы - условия непротекания. На правой и открытой верхней границе производные параметров по нормали к ним полагаются равными нулю. Эти условия позволяют получить стационарное решение методом установления.

В начальный момент поток во всей расчетной области имеет те же значения давления, температуры и скорости, что и на входе в расчетную область.
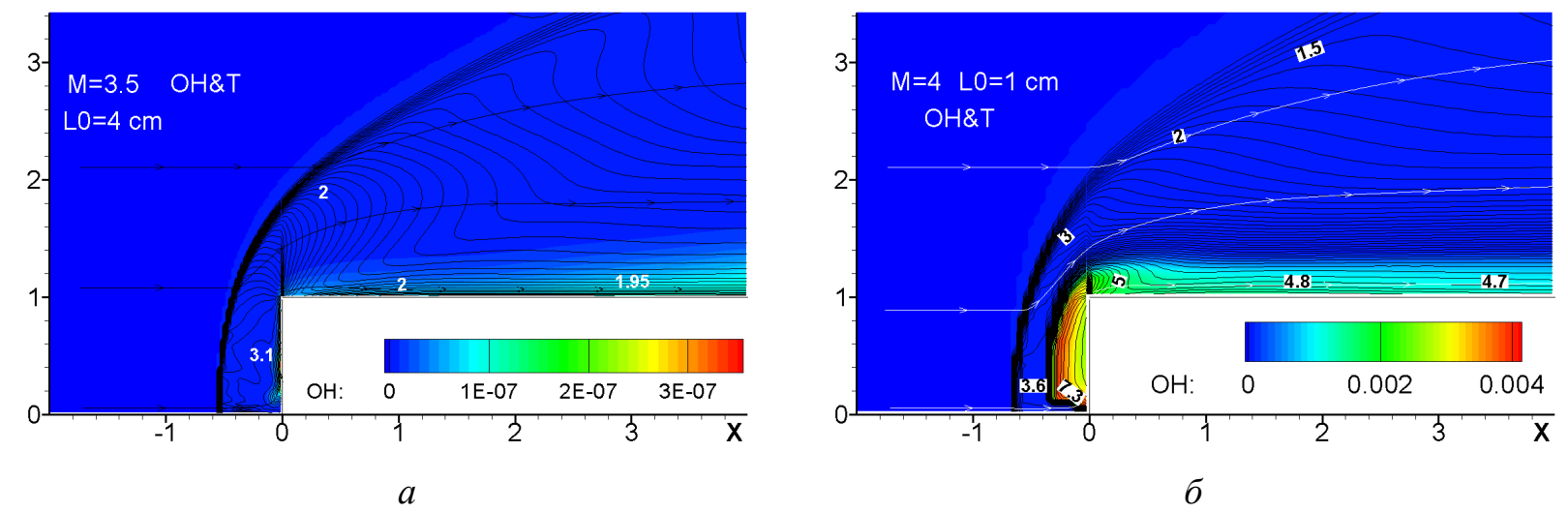

Рис. 5. Линии тока и изотермы на фоне массовой концентрации радикала ОН: $a-\mathrm{M}_{0}=3.5$, $r_{0}=4 \mathrm{~cm} ; \sigma-\mathrm{M}_{0}=4, r_{0}=1 \mathrm{~cm}$

\section{1. Обтекание цилиндра в открытом пространстве}

Натекание сверхзвукового потока на торцевую стенку приводит к формированию отошедшей ударной волны, за которой происходит торможение потока. Кинетическая энергия потока переходит в тепловую, обеспечивая рост температуры и давления в газе. Однако при числе Маха $\mathrm{M}_{0}=3.5$ это не приводит к воспламенению стехиометрической смеси паров ке- 
росина в воздухе (рис. $5, a$ ). Температура газа перед стенкой возрастает при этом примерно в 3 раза. При $\mathrm{M}_{0}=4$ температура за волной увеличивается в 3.6 раза, что обеспечивает воспламенение и стационарное горение керосина, но только у поверхности цилиндра (рис. 5, б). Это горение является детонационным, поскольку его инициирование обеспечивает отошедшая ударная волна. В данном случае горение слабо влияет на отход этой волны от торцевой стенки.

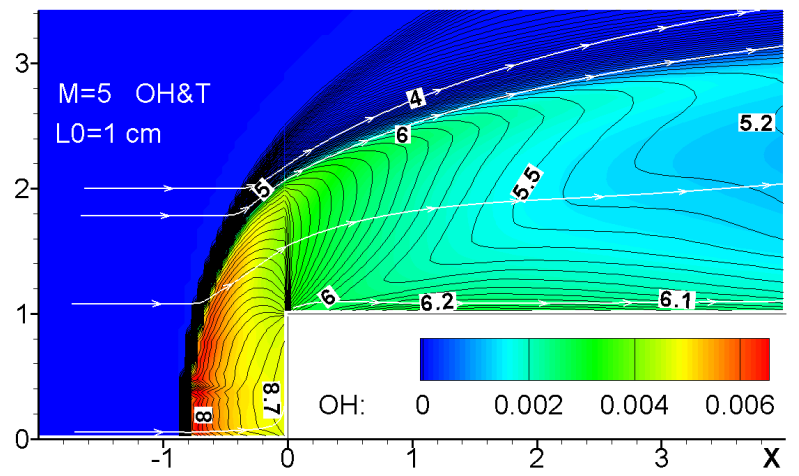

$a$

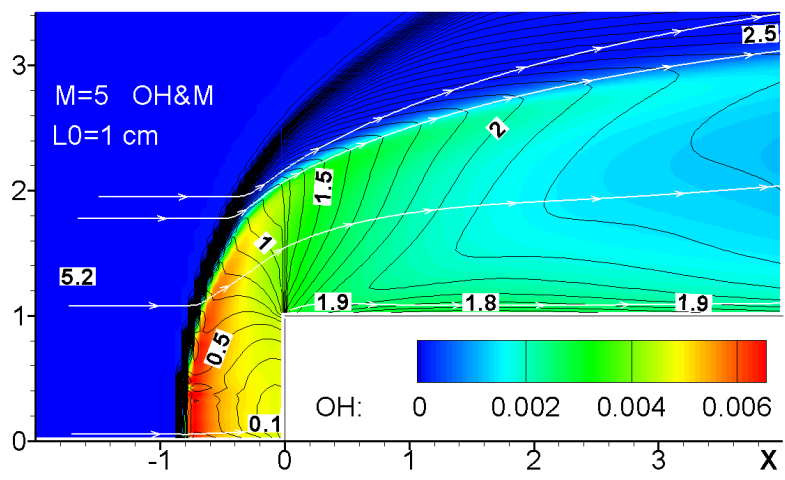

$\sigma$

Рис. 6. Расчет по схеме Годунова: линии тока, изотермы $(a)$ и линии постоянного числа Маха (б) на фоне массовой концентрации радикала $\mathrm{OH}$ при $r_{0}=1$ см и $\mathrm{M}_{0}=5$
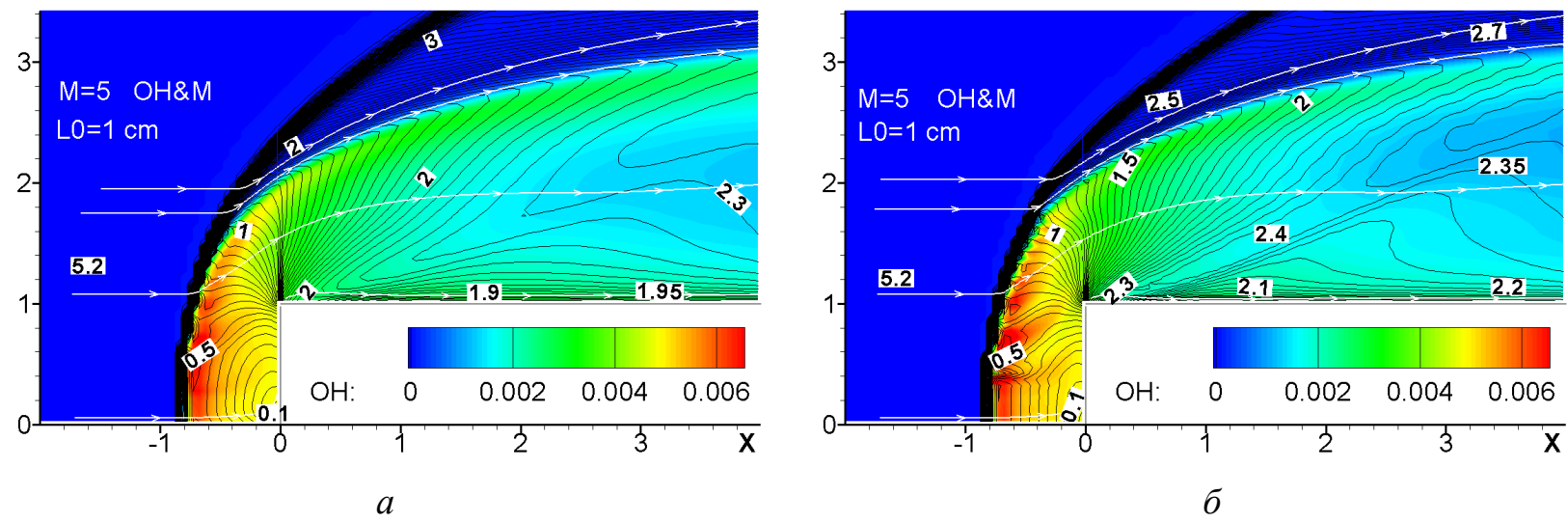

Рис. 7. Линии тока и постоянного числа Маха на фоне массовой концентрации радикала ОН при $r_{0}=1 \mathrm{~cm}$ и $\mathrm{M}_{0}=5: a$-расчет с использованием $\beta$-модификации при $\beta=2 ; \sigma$-расчет по схеме Колгана
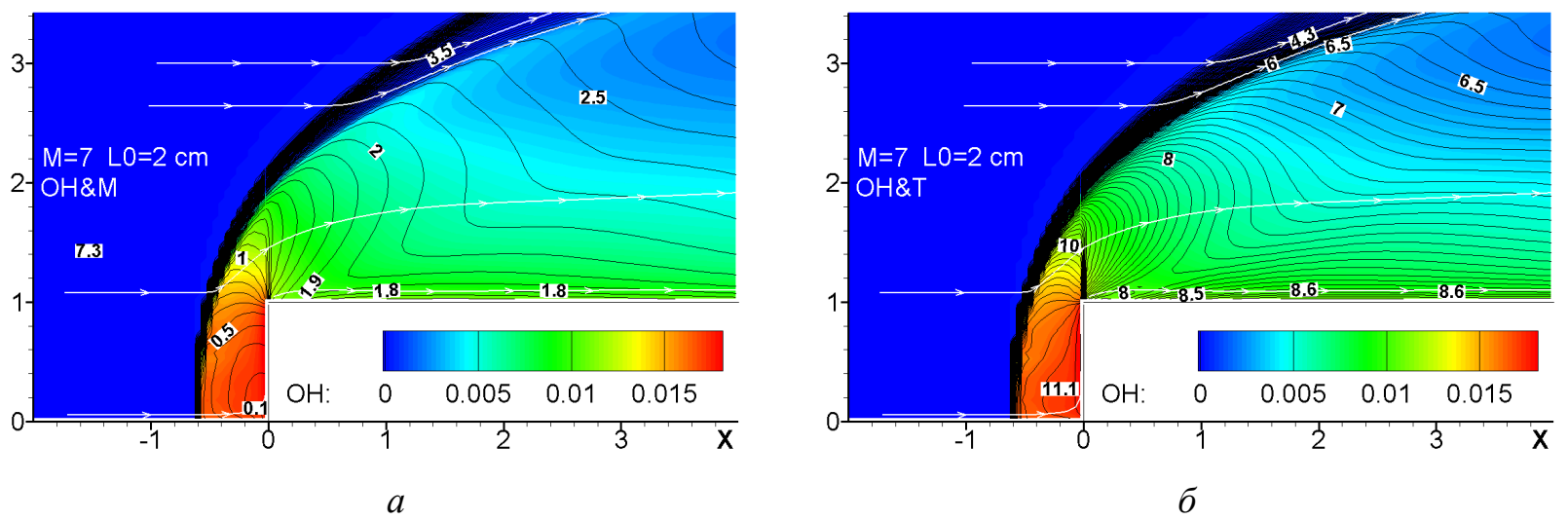

Рис. 8. Расчет по схеме Годунова: $a$ - линии тока и постоянного числа Маха; $\sigma$ - изотермы на фоне массовой концентрации радикала ОН при $r_{0}=2$ см и $\mathrm{M}_{0}=7$ 
Интенсивная стационарная детонация формируется при $\mathrm{M}_{0}=5$ (рис. 6 ). В расчете с использованием $\beta$-модификации получена аналогичная картина обтекания (рис. $7, a$ ). По причинам, изложенным в [34 - 35], схема Колгана приводит к слабо пульсирующему детонационному режиму горения, мгновенная фотография которого (рис. 7,6 ) близка к картине течения по схеме Годунова и $\beta$-модификации. В окрестности оси симметрии воспламенение происходит непосредственно за отошедшей ударной волной. Затем контактный разрыв, ограничивающий область продуктов горения, отходит от головной ударной волны. С ростом числа Маха набегающего потока контактный разрыв сближается с отошедшей ударной волной, увеличивая радиус области, занятой продуктами горения (рис. 8).

\section{2. Обтекание цилиндра в канале постоянного сечения}

В канале постоянного сечения режим обтекания цилиндра дополнительно зависит от радиуса канала $R_{\mathrm{ch}}$. При $R_{\mathrm{ch}}=5$ картина течения и результат воспламенения принципиально не отличается от той, что формируется в неограниченном пространстве, несмотря на то, что в данном случае источником воспламенения может служить и отраженная от стенки канала ударная волна (рис. $9, a$ ). Однако даже при $\mathrm{M}_{0}=6$ значительная часть поступающей смеси не воспламеняется (рис. 9, б).

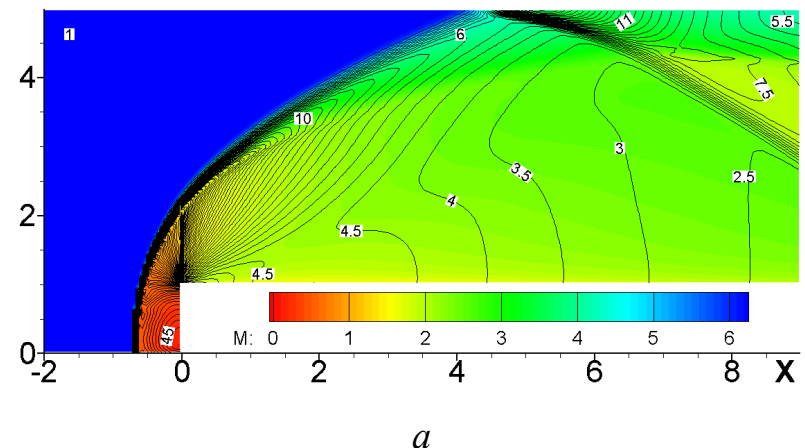

$a$

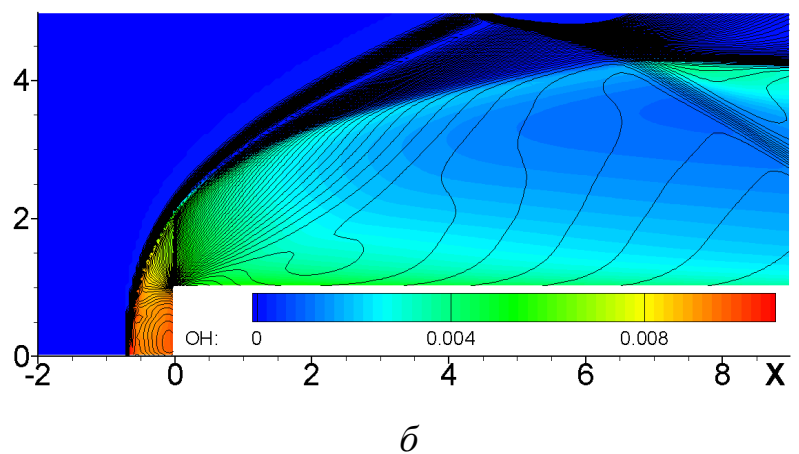

$\sigma$

Рис. 9. Изобары на фоне распределения числа Маха $(a)$ и изохоры на фоне массовой концентрации радикала $\mathrm{OH}\left(\right.$ б) при $r_{0}=2$ см и $\mathrm{M}_{0}=6$

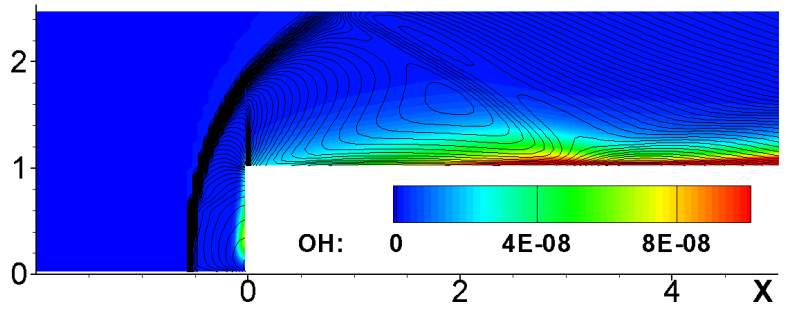

$a$

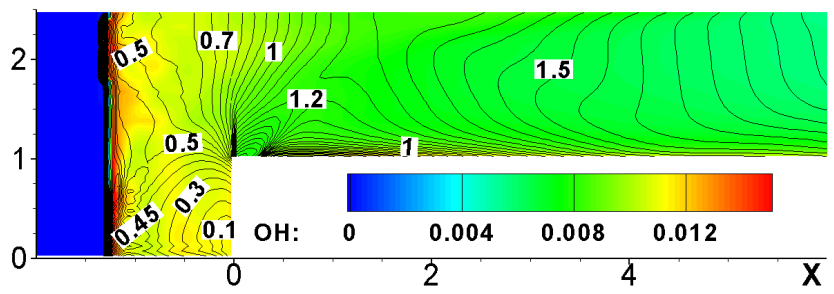

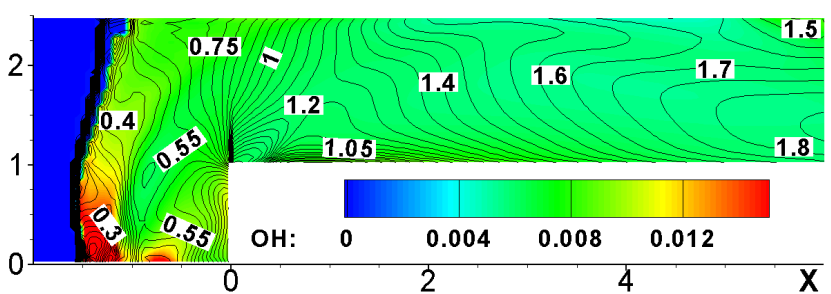

6

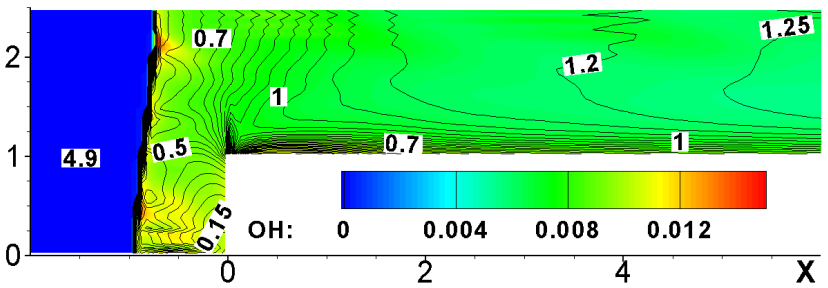

2

Рис. 10. Линии постоянного числа Маха на фоне массовой концентрации радикала ОН при $r_{0}=2$ см и $\mathrm{M}_{0}=3.5(a), 4($ б), 5 (b), 6 (2) 
В трубе с $R_{\mathrm{ch}}=2.5$ детонационное горение формируется, начиная с числа Маха $\mathrm{M}_{0}=4$ (рис. 10). При этом детонация распространяется по трубе навстречу потоку. Ее скорость снижается с ростом $\mathrm{M}_{0}$. При $\mathrm{M}_{0}=6$ положение ударного фронта меняется незначительно, однако картина течения остается существенно нестационарной из-за поперечных к набегающему потоку пульсаций за головным ударным фронтом.

Инициирование детонационной волны в канале облегчается за счет отраженных ударных волн. Дополнительное воспламенение происходит, во-первых, у стенки трубы за отраженной волной $\mathrm{S}$ (рис. 11,a). Кроме того, смесь воспламеняется у поверхности цилиндра за точкой отражения волны S. B результате отражение головной ударной волны от стенки трубы и волны $\mathrm{S}$ от поверхности цилиндра приобретает нерегулярный характер. Формируются маховские ударные волны $\mathrm{G}$ и $\mathrm{D}$, распространяющиеся навстречу потоку (рис. 11,б). Тройная точка $\mathrm{K}$ перемещается вниз по фронту головной ударной волны по мере приближения волны D к угловой точке контура цилиндрического тела и, в конечном счете, перестает существовать вместе с тройной точкой L и волной $\mathrm{D}$.
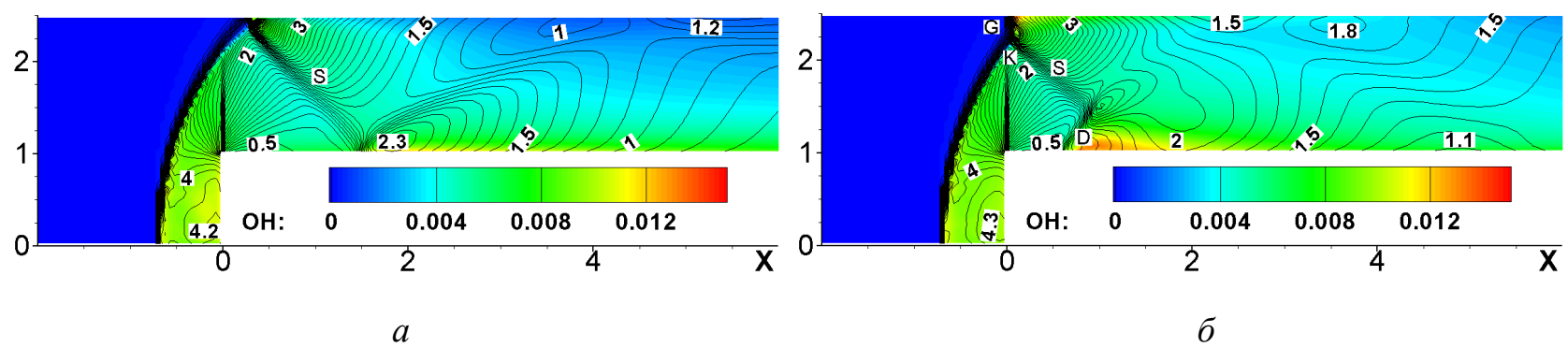

Рис. 11. Изохоры на фоне массовой концентрации радикала ОН при $r_{0}=2$ см и $\mathrm{M}_{0}=6$ в два последовательных момента времени

\section{4. Заключение}

В рамках принятых моделей движения газа и кинетики горения паров керосина численно показано, что в открытом пространстве детонационное горение стехиометрической смеси возникает за фронтом отошедшей ударной волны при числе Маха набегающего потока более 3.5. Радиус области, занятой продуктами горения, растет с увеличением числа Маха набегающего потока.

В коаксиальном канале постоянного сечения инициированию детонации способствует воспламенение газа в области отражения ударных волн от стенки трубы и боковой поверхности центрального цилиндрического тела. При числе Маха набегающего потока более 4 детонационное горение стехиометрической смеси паров керосина с воздухом происходит во всей полости трубы за лидирующим ударным фронтом, если диаметр канала не более, чем в два с половиной раза превосходит диаметр цилиндра. Картина обтекания цилиндра и, в частности, положение ударного фронта детонации стабилизируются с ростом числа Маха набегающего потока.

Результаты позволяют обосновать параметры сопла с центральным телом для сверхзвуковой прямоточной камеры детонационного горения керосина. 


\section{Приложение 1}

Упрощенный кинетический механизм высокотемпературного горения керосина в воздухе: $k=A T^{n} \exp (-E / R T)$

\begin{tabular}{|c|c|}
\hline № & Reaction \\
\hline 1 & $\mathrm{~N}-\mathrm{C} 10 \mathrm{H} 22+\mathrm{OH}=>\mathrm{T}-\mathrm{C} 10 \mathrm{H} 21+\mathrm{H} 2 \mathrm{O}$ \\
\hline 2 & $\mathrm{~N}-\mathrm{C} 10 \mathrm{H} 22+\mathrm{OH}=>\mathrm{S}-\mathrm{C} 10 \mathrm{H} 21+\mathrm{H} 2 \mathrm{O}$ \\
\hline 3 & $\mathrm{~N}-\mathrm{C} 10 \mathrm{H} 22+\mathrm{H}=>\mathrm{T}-\mathrm{C} 10 \mathrm{H} 21+\mathrm{H} 2$ \\
\hline 4 & $\mathrm{~N}-\mathrm{C} 10 \mathrm{H} 22+\mathrm{H}=>\mathrm{S}-\mathrm{C} 10 \mathrm{H} 21+\mathrm{H} 2$ \\
\hline 5 & $\mathrm{~T}-\mathrm{C} 10 \mathrm{H} 21=>\mathrm{P}-\mathrm{C} 6 \mathrm{H} 13+\mathrm{P}-\mathrm{C} 4 \mathrm{H} 8$ \\
\hline 6 & $\mathrm{~S}-\mathrm{C} 10 \mathrm{H} 21=>\mathrm{P}-\mathrm{C} 7 \mathrm{H} 15+\mathrm{C} 3 \mathrm{H} 6$ \\
\hline 7 & $\mathrm{P}-\mathrm{C} 7 \mathrm{H} 15=>\mathrm{P}-\mathrm{C} 4 \mathrm{H} 9+\mathrm{C} 3 \mathrm{H} 6$ \\
\hline 8 & $\mathrm{P}-\mathrm{C} 7 \mathrm{H} 15=>\mathrm{P}-\mathrm{C} 4 \mathrm{H} 8+\mathrm{N}-\mathrm{C} 3 \mathrm{H} 7$ \\
\hline 9 & $\mathrm{P}-\mathrm{C} 7 \mathrm{H} 15=>\mathrm{P}-\mathrm{C} 5 \mathrm{H} 10+\mathrm{C} 2 \mathrm{H} 5$ \\
\hline 10 & $\mathrm{P}-\mathrm{C} 6 \mathrm{H} 13=>\mathrm{P}-\mathrm{C} 4 \mathrm{H} 9+\mathrm{C} 2 \mathrm{H} 4$ \\
\hline 11 & $\mathrm{P}-\mathrm{C} 5 \mathrm{H} 10=>\mathrm{C} 2 \mathrm{H} 5+\mathrm{C} 3 \mathrm{H} 5$ \\
\hline 12 & $\mathrm{P}-\mathrm{C} 4 \mathrm{H} 9<=>\mathrm{C} 2 \mathrm{H} 5+\mathrm{C} 2 \mathrm{H} 4$ \\
\hline 13 & $\mathrm{C} 3 \mathrm{H} 5+\mathrm{CH} 3<=>\mathrm{P}-\mathrm{C} 4 \mathrm{H} 8$ \\
\hline 14 & $\mathrm{C} 3 \mathrm{H} 8+\mathrm{H}<=>\mathrm{N}-\mathrm{C} 3 \mathrm{H} 7+\mathrm{H} 2$ \\
\hline 15 & $\mathrm{C} 2 \mathrm{H} 5+\mathrm{CH} 3<=>\mathrm{C} 3 \mathrm{H} 8$ \\
\hline 16 & $\mathrm{~N}-\mathrm{C} 3 \mathrm{H} 7<=>\mathrm{CH} 3+\mathrm{C} 2 \mathrm{H} 4$ \\
\hline 17 & $\mathrm{~N}-\mathrm{C} 3 \mathrm{H} 7<=>\mathrm{H}+\mathrm{C} 3 \mathrm{H} 6$ \\
\hline 18 & $\mathrm{C} 3 \mathrm{H} 6+\mathrm{OH}<=>\mathrm{C} 3 \mathrm{H} 5+\mathrm{H} 2 \mathrm{O}$ \\
\hline 19 & $\mathrm{C} 3 \mathrm{H} 5+\mathrm{H}=>\mathrm{C} 3 \mathrm{H} 4+\mathrm{H} 2$ \\
\hline 20 & $\mathrm{C} 3 \mathrm{H} 4+\mathrm{OH}=>\mathrm{C} 3 \mathrm{H} 3+\mathrm{H} 2 \mathrm{O}$ \\
\hline 21 & $\mathrm{C} 3 \mathrm{H} 3+\mathrm{O}<=>\mathrm{C} 2 \mathrm{H} 2+\mathrm{CO}+\mathrm{H}$ \\
\hline 22 & $\mathrm{C} 2 \mathrm{H} 6+\mathrm{OH}<=>\mathrm{C} 2 \mathrm{H} 5+\mathrm{H} 2 \mathrm{O}$ \\
\hline 23 & $\mathrm{C} 2 \mathrm{H} 6+\mathrm{H}<=>\mathrm{C} 2 \mathrm{H} 5+\mathrm{H} 2$ \\
\hline 24 & $\mathrm{C} 2 \mathrm{H} 5+\mathrm{O} 2<=>\mathrm{C} 2 \mathrm{H} 4+\mathrm{HO} 2$ \\
\hline 25 & $\mathrm{C} 2 \mathrm{H} 4+\mathrm{O}<=>\mathrm{CH} 3+\mathrm{HCO}$ \\
\hline 26 & $\mathrm{C} 2 \mathrm{H} 4+\mathrm{OH}<=>\mathrm{C} 2 \mathrm{H} 3+\mathrm{H} 2 \mathrm{O}$ \\
\hline 27 & $\mathrm{C} 2 \mathrm{H} 4+\mathrm{H}<=>\mathrm{C} 2 \mathrm{H} 3+\mathrm{H} 2$ \\
\hline 28 & $\mathrm{C} 2 \mathrm{H} 3+\mathrm{O} 2<=>\mathrm{C} 2 \mathrm{H} 2+\mathrm{HO} 2$ \\
\hline 29 & $\mathrm{C} 2 \mathrm{H} 3+\mathrm{O} 2<=>\mathrm{CH} 2 \mathrm{O}+\mathrm{HCO}$ \\
\hline 30 & $\mathrm{C} 2 \mathrm{H} 2+\mathrm{O}<=>\mathrm{HCCO}+\mathrm{H}$ \\
\hline 31 & $\mathrm{C} 2 \mathrm{H} 2+\mathrm{O}<=>\mathrm{T}-\mathrm{CH} 2+\mathrm{CO}$ \\
\hline 32 & $\mathrm{HCCO}+\mathrm{O} 2<=>2 \mathrm{CO}+\mathrm{OH}$ \\
\hline 33 & $\mathrm{HCCO}+\mathrm{O} 2<=>\mathrm{HCO}+\mathrm{CO} 2$ \\
\hline 34 & $\mathrm{HCCO}+\mathrm{H}<=>\mathrm{P}-\mathrm{CH} 2+\mathrm{CO}$ \\
\hline 35 & $\mathrm{CH} 4+\mathrm{OH}<=>\mathrm{CH} 3+\mathrm{H} 2 \mathrm{O}$ \\
\hline 36 & $\mathrm{CH} 4+\mathrm{O}<=>\mathrm{CH} 3+\mathrm{OH}$ \\
\hline 37 & $\mathrm{CH} 4+\mathrm{H}<=>\mathrm{CH} 3+\mathrm{H} 2$ \\
\hline 38 & $\mathrm{CH} 3 \mathrm{O}+\mathrm{M}=>\mathrm{CH} 2 \mathrm{O}+\mathrm{H}+\mathrm{M}$ \\
\hline 39 & $\mathrm{CH} 3+\mathrm{HO} 2<=>\mathrm{CH} 3 \mathrm{O}+\mathrm{OH}$ \\
\hline 40 & $\mathrm{CH} 3+\mathrm{O}<=>\mathrm{CH} 2 \mathrm{O}+\mathrm{H}$ \\
\hline 41 & $\mathrm{OH}+\mathrm{CH} 3<=>\mathrm{P}-\mathrm{CH} 2+\mathrm{H} 2 \mathrm{O}$ \\
\hline 42 & $2 \mathrm{CH} 3<=>\mathrm{C} 2 \mathrm{H} 5+\mathrm{H}$ \\
\hline 43 & $\mathrm{CH} 2 \mathrm{O}+\mathrm{OH}=>\mathrm{HCO}+\mathrm{H} 2 \mathrm{O}$ \\
\hline 44 & $\mathrm{CH} 2 \mathrm{O}+\mathrm{H}=>\mathrm{HCO}+\mathrm{H} 2$ \\
\hline 45 & $\mathrm{P}-\mathrm{CH} 2+\mathrm{CO} 2<=>\mathrm{CO}+\mathrm{CH} 2 \mathrm{O}$ \\
\hline 46 & $\mathrm{P}-\mathrm{CH} 2+\mathrm{C} 2 \mathrm{H} 4<=>\mathrm{C} 3 \mathrm{H} 6$ \\
\hline 47 & $2 \mathrm{CH} 3+\mathrm{M}=>\mathrm{C} 2 \mathrm{H} 6+\mathrm{M}$ \\
\hline 48 & $\mathrm{P}-\mathrm{CH} 2+\mathrm{M}<=>\mathrm{T}-\mathrm{CH} 2+\mathrm{M}$ \\
\hline 49 & $\mathrm{~T}-\mathrm{CH} 2+\mathrm{O} 2=>\mathrm{CO} 2+\mathrm{H} 2$ \\
\hline
\end{tabular}

\begin{tabular}{|c|c|c|}
\hline$A$ & $n$ & $E(\mathrm{cal} / \mathrm{mol})$ \\
\hline $1.00 \mathrm{E}+14$ & 0 & 47630 \\
\hline $1.00 \mathrm{E}+14$ & 0 & 49000 \\
\hline $4.50 \mathrm{E}+07$ & 2 & 4995.22 \\
\hline $4.50 \mathrm{E}+07$ & 2 & 4995.22 \\
\hline $1.50 \mathrm{E}+13$ & 0 & 28274.38 \\
\hline $1.50 \mathrm{E}+13$ & 0 & 28274.38 \\
\hline $2.00 \mathrm{E}+13$ & 0 & 28776.29 \\
\hline $2.00 E+13$ & 0 & 28776.29 \\
\hline $4.00 \mathrm{E}+13$ & 0 & 28776.29 \\
\hline $2.50 \mathrm{E}+13$ & 0 & 28776.29 \\
\hline $3.16 \mathrm{E}+16$ & 0 & 80901 \\
\hline $2.50 \mathrm{E}+13$ & 0 & 28824.09 \\
\hline $1.00 \mathrm{E}+13$ & 0 & 0 \\
\hline $1.30 \mathrm{E}+14$ & 0 & 9703.63 \\
\hline $7.00 \mathrm{E}+12$ & 0 & 0 \\
\hline $9.60 \mathrm{E}+13$ & 0 & 31022.94 \\
\hline $1.25 \mathrm{E}+14$ & 0 & 37021.99 \\
\hline $7.90 \mathrm{E}+12$ & 0 & 0 \\
\hline $3.33 E+12$ & 0 & 0 \\
\hline $2.00 \mathrm{E}+07$ & 2 & 998.71 \\
\hline $1.40 \mathrm{E}+14$ & 0 & 0 \\
\hline $7.20 \mathrm{E}+06$ & 2 & 860.42 \\
\hline $1.40 \mathrm{E}+09$ & 1.5 & 7433.08 \\
\hline $1.02 \mathrm{E}+10$ & 0 & -2186.18 \\
\hline $1.36 \mathrm{E}+07$ & 1.88 & 178.78 \\
\hline $3.00 \mathrm{E}+13$ & 0 & 3011.47 \\
\hline $5.40 \mathrm{E}+14$ & 0 & 14913.96 \\
\hline $5.19 \mathrm{E}+15$ & -1.26 & 3307.84 \\
\hline $1.70 \mathrm{E}+29$ & -5.31 & 6493.79 \\
\hline $5.06 \mathrm{E}+06$ & 2.1 & 1570.27 \\
\hline $2.17 \mathrm{E}+06$ & 2.1 & 1570.27 \\
\hline $8.13 E+11$ & 0 & 855.64 \\
\hline $8.13 \mathrm{E}+11$ & 0 & 855.64 \\
\hline $1.50 \mathrm{E}+14$ & 0 & 0 \\
\hline $1.56 \mathrm{E}+07$ & 1.83 & 2772.47 \\
\hline $7.23 \mathrm{E}+08$ & 1.56 & 8484.7 \\
\hline $1.30 \mathrm{E}+04$ & 3 & 8030.59 \\
\hline $5.42 \mathrm{E}+13$ & 0 & 13503.82 \\
\hline $3.78 E+13$ & 0 & 0 \\
\hline $8.43 E+13$ & 0 & 0 \\
\hline $2.50 \mathrm{E}+13$ & 0 & 0 \\
\hline $3.16 \mathrm{E}+13$ & 0.27 & 1821.91 \\
\hline $3.43 E+09$ & 1.18 & -454.11 \\
\hline $1.26 \mathrm{E}+08$ & 1.62 & 2165.39 \\
\hline $1.40 \mathrm{E}+13$ & 0 & 0 \\
\hline $9.64 \mathrm{E}+13$ & 0 & 0 \\
\hline $1.81 \mathrm{E}+13$ & 0 & 0 \\
\hline $1.50 \mathrm{E}+13$ & 0 & 0 \\
\hline $1.20 \mathrm{E}+13$ & 0 & 1481.84 \\
\hline
\end{tabular}




$\begin{array}{ll}50 & \mathrm{~T}-\mathrm{CH} 2+\mathrm{O} 2=>\mathrm{CO}+\mathrm{OH}+\mathrm{H} \\ 51 & \mathrm{~T}-\mathrm{CH} 2+\mathrm{CH} 3<=>\mathrm{C} 2 \mathrm{H} 4+\mathrm{H} \\ 52 & \mathrm{HCO}+\mathrm{OH}<=>\mathrm{CO}+\mathrm{H} 2 \mathrm{O} \\ 53 & \mathrm{HCO}+\mathrm{M}<=>\mathrm{CO}+\mathrm{H}+\mathrm{M} \\ 54 & \mathrm{CO}+\mathrm{OH}<=>\mathrm{CO} 2+\mathrm{H} \\ 55 & \mathrm{H}+\mathrm{O} 2<=>\mathrm{OH}+\mathrm{O} \\ 56 & \mathrm{O}+\mathrm{H} 2<=>\mathrm{OH}+\mathrm{H} \\ 57 & \mathrm{OH}+\mathrm{H} 2<=>\mathrm{H} 2 \mathrm{O}+\mathrm{H} \\ 58 & 2 \mathrm{OH}<=>\mathrm{H} 2 \mathrm{O}+\mathrm{O} \\ 59 & \mathrm{H}+\mathrm{O} 2+\mathrm{M}<=>\mathrm{HO} 2+\mathrm{M} \\ 60 & \mathrm{HO} 2+\mathrm{H}<=>2 \mathrm{OH} \\ 61 & \mathrm{HO} 2+\mathrm{H}<=>\mathrm{H} 2+\mathrm{O} 2 \\ 62 & \mathrm{HO} 2+\mathrm{H}<=>\mathrm{H} 2 \mathrm{O}+\mathrm{O} \\ 63 & \mathrm{~N}-\mathrm{C} 10 \mathrm{H} 22<=>\mathrm{T}-\mathrm{C} 10 \mathrm{H} 21+\mathrm{H} \\ 64 & \mathrm{~N}-\mathrm{C} 10 \mathrm{H} 22<=>\mathrm{S}-\mathrm{C} 10 \mathrm{H} 21+\mathrm{H} \\ 65 & \mathrm{~N}-\mathrm{C} 10 \mathrm{H} 22<=>\mathrm{P}-\mathrm{C} 4 \mathrm{H} 9+\mathrm{P}-\mathrm{C} 6 \mathrm{H} 13 \\ 66 & \mathrm{~N}-\mathrm{C} 10 \mathrm{H} 22<=>\mathrm{N}-\mathrm{C} 3 \mathrm{H} 7+\mathrm{P}-\mathrm{C} 7 \mathrm{H} 15 \\ 67 & \mathrm{~N}-\mathrm{C} 10 \mathrm{H} 22+\mathrm{O} 2<=>\mathrm{S}-\mathrm{C} 10 \mathrm{H} 21+\mathrm{HO} 2 \\ 68 & \mathrm{~N}-\mathrm{C} 10 \mathrm{H} 22+\mathrm{O} 2<=>\mathrm{t}-\mathrm{C} 10 \mathrm{H} 21+\mathrm{HO} 2\end{array}$

\begin{tabular}{|c|c|c|}
\hline $1.30 \mathrm{E}+13$ & 0 & 1481.84 \\
\hline $4.22 E+13$ & 0 & 0 \\
\hline $1.02 E+15$ & 0 & 0 \\
\hline $7.00 E+14$ & 0 & 16802.1 \\
\hline $8.97 E+06$ & 1.5 & -740.92 \\
\hline $9.76 \mathrm{E}+13$ & 0 & 14842.26 \\
\hline $5.12 E+04$ & 2.67 & 6285.85 \\
\hline $1.02 E+08$ & 1.6 & 3298.28 \\
\hline 1. $51 E+09$ & 1.14 & 100.38 \\
\hline $3.54 E+18$ & -0.8 & 0 \\
\hline $1.69 \mathrm{E}+14$ & 0 & 874.76 \\
\hline $4.28 E+13$ & 0 & 1410.13 \\
\hline $3.01 E+13$ & 0 & 1720.84 \\
\hline $8.00 \mathrm{E}+17$ & 0 & 01000.00 \\
\hline $8.00 \mathrm{E}+17$ & $0 \quad 1$ & 01000.00 \\
\hline $3.16 \mathrm{E}+16$ & 0 & 81000.00 \\
\hline $3.16 \mathrm{E}+16$ & 0 & 81000.00 \\
\hline $1.00 \mathrm{E}+14$ & 0 & 47600.00 \\
\hline $1.00 \mathrm{E}+14$ & 0 & 47600.00 \\
\hline
\end{tabular}

\section{Благодарности и ссылки на гранты}

Работа выполнена с использованием суперкомпьютера МГУ «Ломоносов».

\section{Литература}

1. Зельдович Я.Б. К вопросу об энергетическом использовании детонационного горения// Журнал технической физики, 1940, т. 10, вып. 17, с. 1453-1461.

2. Frolov S.M., V.S.Aksenov V.S., Ivanov V.S. Experimental proof of Zel'dovich cycle efficiency gain over cycle with constant pressure combustion for hydrogen-oxygen fuel mixture// International Journal of Hydrogen Energy. 2015. V. 40. Issue 21. Pp. 6970-6975

3. Frolov S.M., V.S.Aksenov V.S., Ivanov V.S., Shamshin I.O. Large-scale hydrogen-air continuous detonation combustor// International Journal of Hydrogen Energy. 2015. V. 40, No. 3, pp. 1616-1623.

4. Tunik Yu.V. Detonation Combustion of Hydrogen in a Convergent-Divergent Nozzle with a Central Coaxial Cylinder// Fluid Dynamics. 2014. Vol. 49. No. 5, pp. 688-693. https://doi.org/10.1134/S0015462814050160

5. Zubin M.A., Tunik Yu.V. About stabilization of hydrogen detonative combustion in a convergentdivergent nozzle// Physical-Chemical Kinetics in Gas Dynamics. 2015. V. 16. No. 3. http://chemphys.edu.ru/issues/2015-16-3/articles/579/

6. Zhuravskaya T.A., Levin V.A. Stabilization of detonation combustion of a high-velocity combustible gas mixture flow in a plane channel// Fluid Dynamics. 2010, Vol. 50, No. 2, pp. 283-293. DOI: $10.1134 / \mathrm{S} 001546281502012 \mathrm{X}$

7. Zhuravskaya T.A., Levin V.A. Investigation of certain techniques for stabilizing detonation waves in a supersonic flow// Fluid Dynamics. 2012. V. 47 . No. 6, pp. 793-801. https://doi.org/10.1134/S0015462812060129

8. Kindracki J, Kobiera A, Wolanski P, Gut Z, Folusiak M, Swiderski K. Experimental and numerical study of the rotating detonation engine in hydrogen-air mixture// Progress in Propulsion Physics. Ed. by L. DeLuca, C. Bonnal, O. Haidn, S. Frolov // Moscow: Torus Press, 2011. V. 2, pp. 555- 582. $864 \mathrm{P}$.

9. Фролов С.М., Аксенов В.С. Переход горения в детонацию в керосигно воздушной смеси // Доклады Академии наук. 2007. Т. 416. № 3. С. 356-359. 
10. Фролов С.М., Аксенов В.С., Иванов В.С. Экспериментальная демонстрация рабочего процесса в импульсно-детонационном жидкостном ракетном двигателе// Химическая физика. 2011. Т. 30. № 8. C. 58-61.

11. Vikram Athreya V., Rajan N.K.S., Manjunatha A., Purushothama H.R. An experimental study on kerosene based pulse detonation engine // International journal of mechanical engineering and technology (IJMET). 2014. V.5, No 9. Pp. 31-35.

12. Kindracki J. Study of detonation initiation in kerosene-oxidizer mixtures in short tubes// Shock Waves. 2014. V. 24. Pp. 603-618. DOI 10.1007/s00193-014-0519-2.

13. Лепихов A.В. Упрощенная кинетическая схема горения RP-1/O2 для CFD расчетов ракетных двигателей//Физико-химическая кинетика в газовой динамике. 2016. Т. 17, № 1. http://chemphys.edu.ru/essues/2016-17-1/articles/626/

14. Федоров А.В., Тропин Д.А. Математическая модель детонационного сгорания пара керосина в окислителе // Физика горения и взрыва. 2012. Т. 48. № 1. С. 47-54.

15. Ковалев В.Л., Ветчинкин А.С., Вагнер А.В. Моделирование воспламенения авиационного керосина ударной волной// Вестник Московского университета. Серия 1: Математика. Механика, издательство Изд-во Моск. ун-та. Серия 1. Математика. Механика. 2014. № 2, с. 70-74

16. Беляев А.А., Басевич В.Я., Фролов С.М. База данных для расчета ламинарного и турбулентного горения воздушных смесей авиационного керосина // Горение и взрыв. 2015. Т.8. № 1. С. 29-36.

17. Старик А.М., Титова Н.С., Торохов С.А. Кинетика окисления и горения сложных углеводородных топлив: авиационный керосин. Физика горения и взрыва. 2013. Т. 49. № 4, с. 12-30.

18. Slavinskaya N. Skeletal mechanism for kerosene combustion with PAH production// AIAA-20080992.

19. Rajasekaran A., Satishkumar G., Babu V. Numerical simulation of the supersonic combustion of kerosene in a model combustor // Progress in Computational Fluid Dynamics, An Int. J. 2009. V.9, No.1, pp. $30-42$.

20. Дубовкин Н.Ф., Маланичева В.Г., Массур Ю.П., Федоров Е.П. Физико-химические и эксплуатационные свойства реактивных топлив: Справочник. М.: Химия, 1985.

21. Герасимов Г.Я., Лосев С.А. Кинетические модели горения керосина и его составляющих// Инженерно-физический журнал. 2005. Т. 78. № 6, с. 14-25.

22. Dagaut P, Cathonnet M. The ignition, oxidation, and combustion of kerosene: A review of experimental and kinetic modeling// Progress in Energy and Combustion Science. 2006. V. 32, pp. 48-92.

23. Wenxuan Huang, Fang Chen, Hong Liu, et al. Modeling chemical mechanism for surrogate jet fuel under scramjet operating conditions// AIAA Paper 2016-0182.

24. Slavinskaya N., Riedel U., Saibov E, Herzler J., Naumann C. Kinetic surrogate model for GTL kerosene// AIAA Paper 2014-0126.

25. Yan Y., Liu Y., Di D., Dai C., Li J. Simplified Chemical Reaction Mechanism for Surrogate Fuel of Aviation Kerosene and Its Verification// Energy and Fuels. 2016. V. 30 (12), pp. 10847-10857.

26. Bikas G, Peters N. Kinetic modeling of n-decane combustion and autoignition: Modeling combustion of n-decane// Combustion and Flame. 2001. V. 126, pp. 1456-1475.

27. Burcat A., Ruscic B. Third millennium ideal gas and condensed phase thermochemical database for combustion with updates from active thermochemical tables. ANL-05/20 and TAE 960. Technion-IIT, Aerospace Engineering, and Argonne National Laboratory, Chemistry Division, 2005.

28. Dente M., Bozzano G., Faravelli T., Marongiu A., Ranzi E. Kinetic modeling of pyrolysis process in gas and condensed phase// Adv. Chem. Eng. 2007. V. 32, pp. 50-168.

29. Lindstedt R.P., Maurice L.Q. Detailed chemical-kinetic model for aviation fuels// Journal of Propulsion and Power. 2000. V. 16 (2), pp. 187-195. 
30. Chang Y., Jia M., Liu Y., Li Y., Xie M. Development of a new skeletal mechanism for n-decane oxidation under engine-relevant conditions based on a decoupling methodology// Combustion and Flame. 2013. V. 160 (8), pp. 1315-1332.

31. Tunik Yu.V. Stabilization of detonation combustion in a high-velocity flow of a hydrogen-oxygen mixture// Fluid Dynamics. 2008. V. 43. No. 6, pp 954-959.

32. Годунов С.К. Разностный метод численного расчета разрывных решений уравнений гидродинамики// Математический сборник. 1959. Т. 47(89). № 3. С. 271-306.

33. Колган В.П. Применение принципа минимальных значений производной к построению конечно-разностных схем для расчета разрывных решений газовой динамики// Ученые записки ЦАГИ. 1972. Т.ІІІІ. № 6. С. 68-77.

34. Tunik Yu.V. Instability of Contact Surface in Cylindrical Explosive Waves// Fluid Mech. Open Acc. 2017. V. 4. No 4. DOI: 10.4172/2476-2296.1000168

35. Tunik Yu.V. Problems of Numerical Modeling on the Basis of Some Modifications of the Godunov's Scheme// Physical-Chemical Kinetics in Gas Dynamics 2018 V.19, No.1. http://chemphys.edu.ru/issues/2018-19-1/articles/701/ 